\title{
From Contagious to Resilient and Beyond: A Periodization of Four Decades of Educational Research on LGBTQ Issues
}

\author{
Sarah Schneider Kavanagh \\ University of Washington \\ U.S. A.
}

ABSTRACT: This article presents a periodization of educational research on lesbian, gay, bisexual, transgender, and queer (LGBTQ) issues between 1970 and 2010. Developed through a frame analysis of 105 educational research reports, the periodization maps ideological and chronological patterns in the conceptual frames of research on LGBTQ issues. Five paradigmatic frames for understanding LGBTQ issues in education are discussed: (a) homosexuality as a social contagion; (b) homosexuality as a private identity; (c) LGB youth as "atrisk"; (d) LGBTQ youth as victims; and (f) LGBTQ youth as resilient. The author calls for an expansion beyond individual-level analyses into investigations of educational practice.

KEYWORDS: gay/lesbian studies; gender studies; LGBT; frame analysis; Queer theory

Method

Five Frames in the Literature

Pre-1970: Homosexuality as a Social Contagion

1970 Onward: Homosexuality as a Private Identity

1985 Onward: LGBTQ Youth as "At-Risk"

2000 Onward: LGBTQ Youth as Victims

2005 Onward: LGBTQ Youth as Resilient

Conclusion: Why Turn to Practice?

References

Author Contact

In June of 2016, the American Educational Research Association (AERA) released a position statement following the mass shooting at a gay nightclub in Orlando, Florida. The statement called on the educational research community to commit itself to building a knowledge base that could support practitioners in combating the pervasive prejudices and biases that contribute to heterosexist violence in the United States.

AERA is aggrieved by the horrific act of bigotry, extremism, and violence in Orlando. The mass murder at the Pulse nightclub is a hate crime that is an assault on the entire LGBTQ community. This and other recent tragedies rooted in hate raise a broad range of societal and policy issues that are at the core of education and education research.... We call on the 
education research community to redouble its commitment to examining how bigotry can be eliminated and respect for diverse communities fostered. (AERA, 2016)

This call for the educational research community to "redouble its commitment" to research on lesbian, gay, bisexual, transgender, and queer (LGBTQ) issues in education comes at the same moment as an exponential increase in the amount and quality of research on LGBTQ issues in education. However, while it is unique to our time to hear mainstream educational research organizations calling for increased research on LGBTQ issues in education, research into LGBTQ issues is not simply a contemporary phenomenon. Educational researchers have been investigating LGBTQ issues since before 1970, and all contemporary research rests on this historical foundation. Research from the 1970s, 1980s, 1990s, and 2000s was scant in comparison what is being produced today. However, as in any other domain, the conceptual assumptions of previous research exert a strong influence on the conceptual framing of contemporary investigations. As the educational research community embarks on a new era of research on LGBTQ issues, having a robust understanding of the history of scholarship in this domain will allow researchers to thoughtfully assess the assumptions that, often invisibly, guide contemporary research.

To this end, the aim of this study is to investigate the conceptual assumptions that have guided educational research on LGBTQ issues over the last half century. This article presents findings from a meta-synthesis of the educational literature on LGBTQ issues in education between 1970 and 2010, focusing specifically on understanding historical trends in how existing research has framed the problems facing LGBTQ youth in educational contexts. Findings are presented as a chronological periodization of paradigms.

The periodization begins with the earliest mentions of homosexuality in educational research in the late 1960s and concludes with literature published as late as 2010 when research on LGBTQ issues began to increase exponentially following a widely publicized string of suicides of LGBTQ youth in the United States. An analysis of the conceptual framing across sampled articles revealed that research on LGBTQ issues in education can be chronologically categorized into periods of research, each period resting on different paradigms for understanding LGBTQ identity. Analysis across periods revealed one metafinding: across all periods, researchers have tended to approach LGBTQ issues through the lens of identity as opposed to practice by investigating questions relating to the experiences, characteristics, beliefs, and achievements of individuals and populations while eschewing questions relating to professional and social practice at a societal, professional, or group level.

Because this study's findings were derived from a systematic review of the literature, the article begins with a description of the review methodology. In addition to describing the study's sampling strategy, the following section describes how frame analysis was used as an analytic methodology for conducting a qualitative meta-synthesis across decades of research literature. 


\section{Method}

As a meta-synthesis of the conceptual framing of research literature, the methodological design of this study comprised four main stages: (a) discovering existing literature; (b) vetting literature using predetermined criteria; (c) coding qualified literature and sorting studies according to their conceptual framing; and (d) analyzing trends in the coded data to determine findings. Each of these stages is described in detail below.

\section{Sampling Strategy and Selection Criteria}

This study draws on 105 journal articles on LGBTQ issues in education that were published between 1969 and 2010. Relevant literature was identified through searches of two educational research databases: ERIC and Education Source. Because the language used to describe LGBTQ people has varied greatly in the years since 1969, the search terms used to locate relevant literature were varied and broad. Search terms included LGBT, LGBTQ, LGB, GLB, GLBT, GLBTQ, gay, lesbian, bisexual, transgender, questioning, queer, sexuality, sexual orientation, sexual identity, homosexuality, and homosexual. The only criterion for the first round of selection was an article's inclusion of a search term in its title or abstract.

Following this first round of selection, studies were selected using the following criteria: (a) the focus of the study was on LGBTQ people or related curricula or policy in educational settings; (b) the study included an analysis of quantitative or qualitative data (purely theoretical treatments of LGBTQ issues were excluded because the study's focus was on the conceptual frames that researchers have brought to data analysis); and (c) the study was published between 1969, the year often referred to as the birth of the modern gay rights movement, and 2010, a year that marked a proliferation of research on LGBTQ issues. Because of the breadth of the research published since 2010, a thorough analysis of research from the present decade was not possible within the confines of this historical review.

The majority of articles in the data set were survey studies. While most of these survey studies employed quantitative research methods (Birkett, Espelage, \& Koenig, 2009; Espelage, Aragon, Birkett, \& Koenig, 2008; Gruber \& Fineran, 2008; Murdock \& Bolch, 2005; Poteat, Espelage, \& Koenig, 2009; Sandfort, Bos, Collier, \& Metselaar, 2010; Walls, Kane, \& Wisneski, 2010; Wilkinson \& Pearson, 2009), a few employed qualitative methods (Adelman \& Woods, 2006). Prior to 2010, qualitative studies that did not rely on surveys as the primary data source were less prevalent in the field overall, and most focused on the individual experiences or beliefs of educators (Dessel, 2010; McCabe \& Rubinson, 2008; 
Payne \& Smith, 2010; Tooms, 2007; Zach, 2010), while a smaller segment of studies focused on the experiences of LGBTQ youth (Davidson, 2009; Lee, 2002; Russell, Muraco, Subramaniam, \& Laub, 2009; Savin-Williams, 2005, 2009).

Almost all research, whether quantitative or qualitative, focused on understanding individual-level, person-centered identities, experiences, and beliefs. A few sampled studies examined LGBTQ related issues in education using an organizational perspective (Fetner \& Kush, 2008; Goodenow, Szalacha, \& Westheimer, 2006; Wilkinson \& Pearson, 2009) or a legal lens (Biegel, 2010; Dennis \& Harlow, 1986). However, these studies are the exception to the rule of individual-centered analyses. Only two sampled studies foregrounded practical activity as a site of meaning making in the lives of LGBTQ youth: Pascoe's (2007) ethnography examining the social practices of masculinity among adolescent boys and DePalma and Atkinson's (2009) investigation of the professional practices of British primary teachers who participated in a curricular intervention aimed at addressing LGBTQ issues with young children.

\section{Analytic Method}

The goal of this study was to review the literature in a way that would uncover how research has conceptualized the nature of the problem posed by gender and sexual diversity in schools. To achieve this goal, an analytic methodology that allowed for the identification and comparison of conceptual frames across a wide swath of literature was needed. Often applied to studies of public policy or communications, a frame analysis is a methodology for uncovering the underlying conceptual frames that undergird descriptions of problems (Fischer, 2003). Kuypers (2009) describes framing as such:

[Framing] is a process whereby communicators...consciously or unconsciously act to construct a point of view that encourages the facts of a given situation to be interpreted by others in a particular manner. Frames operate in four key ways: they define problems, diagnose causes, make moral judgments, and suggest remedies. (p. 190)

A frame analysis of selected research literature on LGBTQ issues in education revealed a periodization of how scholars have framed the problem of sexual diversity in schools over the last half century. To reach this periodization, I first analyzed each selected research report for framing features (Dombos, 2009) by asking and answering the following questions: What is the problem to be solved? Who is affected by it? Who/what causes the problem to appear or reproduce? What solutions to the problem are presented, if any? I then coded frame descriptions for each research report using codes: problems, subjects, causes, and solutions. The next pass at the data was through open coding, which revealed several prevalent themes. A third pass at coding systematically utilized the most prevalent codes that emerged during open coding: contagion, 
privacy, victimization, and resilience. Finally, a chronological sorting of coded data revealed that themes were chronologically organized in the data. These passes at coding eventually resulted in the periodization of frames in the literature.

While analyses produced compelling findings, the study has limitations. Because there has been an exponential increase in scholarship on LGBTQ issues in education over the last 10 years, it was not possible within the confines of this study to fully explore the conceptual frames of contemporary scholarship. Therefore, this article cannot offer interpretation about how recent scholarship has been influenced by historical trends. Future studies are needed to examine the traces of historical paradigms in contemporary scholarship.

\section{Five Frames in the Literature}

A frame analysis uncovered a chronological pattern of conceptual framing in the research literature on LGBTQ issues in education that is presented in Table 1.

Table 1

Five Frames in the Research Literature

Five Frames In the Literature

$\begin{array}{ll}\text { Pre } 1970 & \text { Homosexuality as a social contagion } \\ 1970-1985 & \text { Homosexuality as a private identity } \\ 1985-2000 & \text { LGB youth as "at risk" } \\ 2000- & \text { LGBTQ youth as victims } \\ 2005- & \text { LGBTQ youth as resilient }\end{array}$

The first frame, homosexuality as a social contagion, is comprised of clinical psychology literature, which is focused on finding causes of and cures or treatments for homosexuality. The second frame, homosexuality as a private identity, emerged at around the time the American Psychiatric Association officially removed homosexuality from the Diagnostic and Statistical Manual of Mental Disorders-III (DSM-III). The emergence of this frame marks the beginning of conceptualizing homosexuality as a private identity isolated within an individual. Studies that assume this frame are primarily concerned with two major questions that captivated researchers in the 1970s: (a) whether lesbian and gay individuals should be allowed to teach in public schools and (b) what it means to promote healthy development for same-sex attracted youth. The third frame of 
research, which conceptualizes LGBTQ youth as "at-risk," focuses on documenting LGBTQ students' high risk for suicide, depression, and other negative health outcomes. The fourth frame conceptualizes LGBTQ youth as victims of interpersonal discrimination and investigates the prevalence and effects of homophobic bullying. The fifth and final frame conceptualizes LGBTQ youth as resilient change-agents in their schools and communities.

Each frame is attached to an approximate year during which the conceptual frame appeared as a shaping force in the educational literature. In addition, the first three frames have approximate end dates. End dates do not denote an end to the publication of literature influenced by this frame, but instead an approximate date when the frame stopped being the primary paradigm in contemporary research literature. Consistent with Maher et al.'s (2009) review of research on LGBTQ issues outside of education, this study found that paradigmatic conceptual frames did not disappear from the research. Once introduced into the field, novel conceptual frames continued to shape the way that knowledge was produced even many years after being discredited. Our contemporary conceptualizations of LGBTQ populations still retain the traces of framings that were paradigmatic half a century ago. The two most recently introduced frames were still prevalent in research literature published around 2010 when this historical review concludes and thus do not have end dates. The sections that follow describe how each of these frames emerged in the research literature and how each frame shaped what was possible in educational research on LGBTQ issues.

\section{Pre-1970: Homosexuality as a Social Contagion}

The emergence and development of educational research related to LGBTQ issues cannot be disentangled from broader LGBTQ social movements. Just as the experiences of LGBTQ people were mostly invisible to the U.S. public prior to the Stonewall Riots of 1969, educational research databases are almost free of pre-Stonewall mentions of homosexuality. Aside from the inclusion of homosexuality in a handful of lists of emotional problems and psychological disorders (Abt \& Weissman, 1965), the topic rarely arises outside of a small collection of clinical psychology texts focused on understanding and preventing the childhood "causes" of homosexuality (Evans, 1969; Gundlach, 1969; Hooker, 1969). These early researchers were grounded in the social contagion paradigm, which conceptualized homosexuality as an epidemiological problem. This view of homosexuality as a disease would soon shift in 1973 when the American Psychiatric Association officially de-pathologized homosexuality by removing it from the third edition of the Diagnostic and Statistical Manual of Mental Disorders (DSM-III). Education literature did not see a great deal of scholarship on LGBTQ issues produced prior to 1970. However, the following section describes how the legacy of the social contagion paradigm shaped education research on LGBTQ issues in education for years to come. 


\section{0-1985: Homosexuality as a Private Identity}

Most of the educational research on LGBTQ issues from the 1970s and early 1980 s was exploratory. It existed on the fringes of mainstream educational research and could rarely be described as reliable by any contemporary standards. Although most of the research relied on weak methodologies, these early researchers did succeed in introducing questions that had never been considered before about the rights and responsibilities of lesbian and gay teachers (La Morte, 1975; Mathews, 1973; Ostrander, 1975; Rivera \& Galvan, 1975), what school counselors should do to support the emotional health of gay students (Birk, 1974; Canon, 1973; Ivey, 1972; Killinger, 1971; Rehm \& Rozensky, 1974), whether and how curricula should address homosexuality (Morin, 1974), and if and how the structure of educational institutions contributes to the oppression of gay students (Liebert, 1971).

Researchers in the 1970s pushed against the social contagion paradigm of the 1960 s by framing homosexuality as a private identity. This conceptualization of LGBTQ identity as a private and internal feature of an individual mapped directly onto the right-to-privacy arguments that gay liberationists were making in the political sphere at the time. In order to secure a legal right to privacy, the primary political goal of the Gay Liberation movement in the 1970s, LGBTQ activists had to push against the social contagion paradigm that had permeated perspectives on gays and lesbians prior to 1973 when the DSM-III depathologized homosexuality.

For gay activists at that time, pushing against the social contagion paradigm meant pushing against conceptualizing LGBTQ identity as socially enacted. The emergence of the private identity, which conceptualized LGBTQ identity as an internal feature of an individual, served the contemporary political needs of gay activists fighting for legal privacy rights. The construct of privacy played an important role in debates about LGBTQ issues in education during this time as well. Embroiled in debates over whether gays and lesbians should be allowed to hold positions as teachers, gay activists argued that LGBTQ identity did not render someone unfit to teach. The most common warrant for this argument was that LGBTQ identity was an entirely private identity - unconnected, in all ways, from a person's identity in their place of work. It is in this political environment that LGBTQ issues in education came to be framed around individuals' private worlds.

By far, the most frequently tackled LGBTQ-related educational research questions in the 1970s and 1980s focused on gay teachers. This is not surprising because the Gay Liberation Movement sparked a series of legal battles about whether sexual orientation was adequate grounds to discharge schoolteachers (Eckes \& McCarthy, 2008). These issues were also widely covered in the mainstream press. Legal battles over the rights of gay teachers pushed up against an existing practice in schools across the country of discharging all 
teachers perceived or known to be gay or lesbian (Blount, 2005; Graves, 2009). As the Gay Liberation Movement affected social mores and established employment practices, educational researchers began asking questions like the following: What is the school's reaction when homosexuality is a trait of a teacher (Mathews, 1973, p. 3)? Under what circumstances should gay teachers be discharged from teaching in the public schools (La Morte, 1975; Rivera \& Galvan, 1975)? Do gay teachers have a duty to keep their sexual orientation private (Ostrander, 1975)? By the 1980s, these questions were frequently being asked in the field of education law (Dennis \& Harlow, 1986) as legal scholars weighed the individual liberties of LGBTQ teachers against broader public attitudes towards homosexuality.

In addition to investigations into the rights and responsibilities of gay teachers, a robust body of literature for school counselors emerged in the 1970s addressing the social and emotional needs of gay adolescents. Even after the American Psychiatric Association removed homosexuality from the DSM-III in 1973, much of the research literature on school counseling described strategies for "changing" same-sex attracted youth (Birk, 1974; Rehm \& Rozensky, 1974). However, while the change-oriented approach to counseling gay and lesbian youth was prevalent (and still exists today), the 1970s also saw the emergence of voices stating that school counselors could better serve gay youth by reevaluating counselors' own attitudes towards gay people and increasing knowledge about the experiences of gay people (Canon, 1973; Killinger, 1971), and referring youth to gay organizations (Ivey, 1972).

Curriculum research relating to LGBTQ issues has always been sparse. In the 1970s, researchers began investigating how and whether curriculum could be used to educate students about homosexuality. Contemporary researchers can acquire knowledge about how little was known in the 1970s by examining the hypotheses tested in these early curriculum studies. One study, for example, investigated whether participating in a unit on homosexuality changed high school students' "levels of masculinity and femininity" (Greenberg, 1974). (It, unsurprisingly, did not). Another less dated study revealed that educational programs on homosexuality, including gay speakers, significantly changed the attitudes of students towards gay people (Morin, 1974).

Research on LGBTQ issues in education covered a range of topics in the 1970s, including teachers, students, and curricula. However, across all topics, there was a common shift in how LGBTQ identity was understood. Abandoning the frame of homosexuality as a social contagion, scholarship in the 1970s framed homosexuality as a fixed, discrete, and private identity. While this shift in frame supported the fight by gay liberationists for expanded rights to a legal private sphere, it also imposed rigid limits on the conditions under which rights to privacy could exist. The logic of the private identity frame did succeed in expanding employment protections by supporting gay and lesbian teachers' right to privacy. However, along with supporting a right to privacy, the logic of the private identity frame also supported the requirement of privacy. If a teachers' lesbian or gay identity did in some way affect their performance in the classroom, 
their employment would no longer be protected. The legacy of this framing continues to affect teachers today (Kahn \& Gorski, 2016). A significant growth in the volume and sophistication of educational research on LGBTQ issues occurred following the 1970s. However, the dominant paradigm of understanding homosexuality as a private identity unconnected to social and practical activity would continue to characterize the research agenda for years to come.

\section{5-2000: LGBTQ Youth as "At-Risk"}

The third frame to emerge in LGBTQ education research arose in the mid1980s. This frame positioned LGBTQ youth as "youth at risk" and focused on identifying their high risks for negative social, academic, and health outcomes (Center for Population Options, 1992; Hetrick \& Martin, 1987; Remafedi, 1987; Robinson, 1994; Savin-Williams, 1994). Like other youth populations that have been labeled as "at risk," research on LGBTQ youth that adopted the at-risk frame located both the problem and the intervention site within individual adolescents. Te Riele (2006) has criticized the use of the "youth-at-risk" frame, arguing that it leads to a focus on what is wrong with individuals rather than what is wrong with the contexts of social practice and collective activity in which those individuals live. Te Riele argues that, by locating problems within individuals rather than their social context, scholarship that adopts the "youth-at-risk" frame can promote stereotypes and sometimes even moral panic about the negative influence that youth labeled "at risk" may have on society.

Though problematic because of the exclusive use of the youth-at-risk frame, early research did identify troubling trends in the experiences of LGBTQ youths and significant disparities between LGBTQ youth and their heterosexual peers. This research also prompted two decades of research and the development of a valuable body of knowledge on the experiences of LGBTQ adolescents. The most influential and widely cited study that adopted the at-risk frame was the 1989 U.S. Department of Health and Human Services study of the prevalence of suicide among gay and lesbian adolescents. This report cited suicide as the leading cause of death for adolescent gays and lesbians. It revealed that gay and lesbian youth were two to six times more likely to attempt suicide than heterosexual youth and that the suicides of lesbians and gays accounted for more than $30 \%$ of all teen suicides. This widely publicized study received intense media attention and profoundly shaped the direction that research on LGBTQ adolescents would take over the next two decades. Much like earlier research on gay and lesbian adults (Meyer \& Wilson, 2009), the 1989 U.S. Health and Human Services study has been criticized for its use of biased sample populations. However, findings from subsequent and more reliable studies have confirmed that LGBTQ youth are at a significantly higher risk than their heterosexual peers for suicide ideation (D'Augelli \& Hershberger, 1993; Hershberger \& D'Augelli, 1995; Remafedi et al., 1998). 
In the years following the U.S. Health and Human Services report, a series of studies on LGBTQ youth revealed that these youth had a high risk of experiencing many negative social, academic, and health outcomes. D'Augelli and Hershberger (1993) found extremely high instances of depression among lesbian, gay, and bisexual adolescents, with $28 \%$ of females and $41 \%$ of males reporting that they experienced depression. Rotheram-Borus et al. (1994) conducted a study of 131 gay and bisexual adolescent males and found that they were significantly more likely to use alcohol and illegal drugs than heterosexual adolescent males. Victim Services (1991) found that $42 \%$ of adolescent runaways surveyed in their study self-identified as LGBTQ. Perhaps due to the large percentage of LGBTQ adolescents among the population of runaways and homeless youth, Coleman (1989) found evidence across studies on adolescent male prostitution that approximately two out of three male adolescent prostitutes self-identified as gay or bisexual. Many of the at-risk studies were of troubled populations in which LGBTQ youth were overrepresented, not of LGBTQ youths as a whole. Studies like these point to troubling trends. However, they also focus solely on the most troubled LGBTQ youth, ignoring the majority of the population. The tendency to examine only the most troubled portions of the population has been a consistent pattern in research on LGBTQ youth. These same types of sampling biases produced the findings used to support the continued definition of homosexuality as a mental illness until 1973 (Meyer \& Wilson, 2009).

Educational research on LGBTQ youth also utilized the youth-at-risk frame. Studies in education described a likelihood of poor academic performance, truancy, and non-completion for LGBTQ youth (Hunter \& Schaecher, 1990; Martin \& Hetrick, 1988; Price \& Telljohann, 1991). In 1987, Remafedi found that $40 \%$ of his sample of gay and bisexual male adolescents had problems with truancy, $80 \%$ were experiencing 'declining school performance,' and $30 \%$ had dropped out of school completely. These early studies brought attention to LGBTQ students in U.S. schools, a population that had previously been largely ignored by the research community. However, while highlighting previously unexplored issues, research that framed LGBTQ youth as at-risk also introduced LGBTQ students into the research literature as a population whose defining characteristics were proclivities towards drugs, alcohol, depression, prostitution, homelessness, suicide, and academic failure. The introduction of the youth-at-risk frame would profoundly shape the way that LGBTQ youth were framed for decades. Well into the 2000s, the effectiveness of educational interventions aimed at LGBTQ youth was determined by whether the intervention decreased incidence of depression, non-completion, drug and alcohol use, and suicidal ideation (Goodenow et al., 2006; Lee, 2002; Walls, Freedenthal, \& Wisneski, 2008). While our contemporary conceptualizations of what it means to effectively educate LGBTQ youth have shifted in the $21^{\text {st }}$ century, traces of the "youth at risk" frame continue to shape contemporary research. 


\section{Onward: LGBTQ Youth as Victims}

At the start of the 21st century, researchers were no longer satisfied with uncovering LGBTQ youths' high risk for experiencing negative outcomes and began asking why these outcomes were so prevalent. What was causing LGBTQ youth to be depressed and resort to suicide? This new perspective shifted the site of the problem and the potential intervention away from at-risk LGBTQ adolescents, conceptualizing the problem as external to the youth themselves. The vast majority of this research focuses on measuring how LGBTQ youths' high risk for negative outcomes is influenced by (a) peer-to-peer bullying and harassment and (b) LGBTQ students' belief that their teachers care about them. This new frame for understanding LGBTQ youth experience continues to conceptualize LGBTQ youth as being a population at risk, but it begins to widen the scope of analysis from the personal to the interpersonal. By examining LGBTQ students' beliefs about their teachers and LGBTQ youths' experiences of peer-to-peer bullying, researchers have begun to see the experiences of individuals as contextually embedded in systems of activity that include more than one isolated individual.

Through analysis of several recent survey studies, researchers have found significant correlations between the LGBTQ students' experience of interpersonal victimization and their experience of negative outcomes like depression, drug and alcohol use, and academic failure. Williams, Connolly, Pepler, \& Craig (2005) findings suggested that while LGBTQ adolescents are more likely to experience symptoms of depression than their heterosexual peers, these symptoms are more highly correlated with their experiences of victimization and lack of supportive relationships with peers and family members than with their sexual orientation. Birkett et al. (2009) found that a lack of homophobic teasing and bullying combined with students' belief that their teachers respected and cared about them significantly decreased the correlation between sexual orientation status and depression, drug use, suicidality, and truancy. Kosciw, Greytak, Diaz, and Bartkiewicz (2009) found that LGBTQ students who could identify supportive teachers were more likely to feel safe at school, have a sense of school belonging, receive higher grades, and have higher educational aspirations. They were also less likely to miss school, be harassed or assaulted at school, or feel victimized at school.

These studies are a sampling of the myriad survey studies from the last decade that have found correlations between the prevalence of interpersonal discrimination and the negative experiences of LGBTQ youth (Advocates for Children, Inc., 2005; Espelage et al., 2008; Gruber \& Fineran, 2008; Morrison \& L'Heureux, 2001; Murdock \& Bolch, 2005; Poteat et al., 2009; Russell, Seif, \& Truong, 2001; Sandfort et al., 2010; Walls et al., 2010; Wilkinson \& Pearson, 2009). All of the studies that employ this frame identify the problem facing 
LGBTQ youth as one of homophobic victimization. Most studies define victimization as peer-to-peer bullying and a few describe the prevalence of teachers turning a blind eye to peer-to-peer bullying. A study by Himmelstein and Bruckner (2010), however, focused on the discriminatory practices of authority figures. They found that non-heterosexual youth experience higher rates of punishment from school officials and police and that these higher rates of punishment are not explained by a greater engagement in illegal or transgressive activities.

Most intervention studies have been firmly grounded in the youth-at-risk conceptual frame and have focused on identifying whether programs such as Gay/Straight Alliances reduce the incidences of negative outcomes like suicidality among LGBTQ youth. However, as the interpersonal discrimination frame has become more widespread, some intervention studies have begun to focus on whether programs lower rates of homophobic bullying and name-calling in schools (Walls et al., 2008). The authors of these studies have found that the presence of Gay/Straight Alliances decreases incidences of homophobic bullying and harassment.

\section{Onward: LGBTQ Youth as Resilient}

The vast majority of the research into LGBTQ youth is grounded in the first four conceptual frames. However, since 2005, an alternative frame for making sense of the experiences of LGBTQ youth in schools has arisen. Several studies have moved beyond risk factors and experiences of interpersonal discrimination to examine resiliency among LGBTQ youth (Davidson, 2009; Russell, 2005; Russell et al., 2009). This trend in the research came about in response to the literature's exclusive focus on the prevalence of experiences of victimization and negative outcomes. Scholars who adopt resiliency frames argue for a need to better understand what factors lead LGBTQ youth to lead healthy adolescent and adult lives (Russell, 2005).

Much of the research utilizing the resiliency frame focuses specifically on youth who act as change agents within their schools. Russell et al. (2009) found that LGBTQ youth became empowered to change their school climates through their involvement in Gay/Straight Alliances. In a study of the experiences of three gender non-conforming adolescent males of color, Davidson (2009) describes how his participants actively engaged in reshaping their school's heterosexist climate. This shift towards understanding LGBTQ youth as empowered change agents within schools has also been examined by some educational philosophers. In conceptual pieces, educational philosophers, such as Talburt (2004) and Hackford-Peer (2010) argue that while the resiliency literature opens up a new discursive position for LGBTQ, it does so by introducing an "out-andproud" foil to previous visions of the "suicidal drop-out" depicted in the youth-atrisk literature. This new discursive position, they argue, continues to draw distinct limits on how LGBTQ students and their schools are imagined. 


\section{Conclusion: Why Turn to Practice?}

This review organizes the research literature on LGBTQ issues in education in a way that illustrates how research has conceptualized the nature of the problem posed by gender and sexual diversity in schools. Through a frame analysis of research literature spanning the last half-century, this investigation revealed a series of ideological and chronological patterns. In this article, these patterns are presented as a periodization of frames in the research literature on LGBTQ issues in education. This periodization illustrates how pivotal historical moments in the struggle for gay rights coincided with the introduction of novel conceptualizations for understanding LGBTQ youth and the problem of sexual diversity in schools. Along with identifying and periodizing five distinct frames, my analysis also revealed that all frames have shared a common focus: individual identity. Across eras, research into LGBTQ issues in schools has focused almost exclusively on examining individuals' defining characteristics, proclivities, experiences, and beliefs. With the introduction of bullying studies, researchers have begun to conceptualize individuals' experiences as embedded in contexts of social practice. However, bullying studies remain primarily focused on understanding how individuals' identities are influenced by social practices - the practices themselves have remained largely unexamined.

Regardless of whether research focuses on privacy, risk, victimization, or resiliency, the research literature during the last 45 years has conceptualized everything from shame and heterosexism to pride and academic achievement as attributes of individuals and not byproducts of social practice and collective activity. Understanding trends in the experiences of individuals helps to identify disparities across communities; however, it does little to support practitioners in understanding how to change those disparities. In order to better understand how to interrupt inequitable disparities between LGBTQ and heterosexual students, educational researchers need to develop a body of knowledge about phenomena affecting LGBTQ youth at the level of social practice. Since any shaping of social practices at the student level would require targeted work from educational professionals, the field would benefit from developing knowledge about how the professional practices of educators reinforce or interrupt inequitable disparities between LGBTQ and heterosexual students. If in the last half-century educational researchers have built a body of knowledge that illuminates the distinct experiences of LGBTQ students and teachers, perhaps educational researchers can spend the next 50 years deepening our understanding about how those experiences are constructed through social and professional practice.

\section{References}


Abt, L. E., \& Weissman, S. L. (1965). Acting out: Theoretical and clinical aspects. New York, NY: Grune and Stratton.

Adelman, M., \& Woods, K. (2006). Identification without intervention: Transforming the anti-LGBTQ school climate. Journal of Poverty, 10(2). 526.

Advocates for Children. (2005, October). In harm's way: A survey of lesbian, gay, bisexual, and transgender students who speak about harassment and discrimination in New York City schools. Retrieved from http://www.advocatesforchildren.org/sites/default/files/library/in_harmes_way _lgbt_report_2005.pdf?pt=1

American Educational Research Association (2016). Statement by AERA executive director Felice J. Levine on the terror attack in Orlando. Retrieved from http://www.aera.net/Newsroom/News-Releases-and-Statements/ Statement-by-AERA-Executive-Director-Felice-J-Levine-on-the-TerrorAttack-in-Orlando

Biegel, S. (2010). The right to be out: Sexual orientation and gender identity in America's public schools. Minneapolis, MN: University of Minnesota Press.

Birk, L. (1974). Group psychotherapy for men who are homosexual. Journal of Sex and Marital Therapy, 1(1). 29-51.

Birkett, M., Espelage, D. L., \& Koenig, B. (2009). LGB and questioning students in schools: The moderating effects of homophobic bullying and school climate on negative outcomes. Journal of Youth and Adolescence, 38. 989-1000.

Blount, J. M. (2005). Fit to teach: Same-sex desire, gender, and school work in the twentieth century. Albany, NY: State University of New York Press.

Canon, H. J. (1973). Gay students. Vocational Guidance Quarterly, 21(3). 181185.

Center for Population Options. (1992). Lesbian, gay and bisexual youth: At risk and underserved. Washington, DC: Author.

Coleman, E. (1989). The development of male prostitution activity among gay and bisexual adolescents. Journal of Homosexuality, 17(1-2), 131-149.

D'Augelli, A. R., \& Hershberger, S. L. (1993). Lesbian, gay, and bisexual youth in community settings: Personal challenges and mental health problems. American Journal of Community Psychology, 21, 421-448.

Davidson, S. M. (2009). Mouths wide shut: Gender-quiet teenage males on gender-bending, gender-passing and masculinities. International Review of Education, 55, 615-631.

Dennis, D., \& Harlow, R. (1986). Gay youth and the right to education. Yale Law and Policy Review, 7(2), 446-478. 
DePalma, R., \& Atkinson, E. (2009). Interrogating heteronormativity in primary schools: The work of the No Outsiders project. Stoke on Trent, UK: Trentham Books.

Dessel, A. B. (2010). Effects of intergroup dialogue: Public school teachers and sexual orientation prejudice. Small Group Research, 41(5), 556-592.

Dombos, T. (2009). Critical frame analysis: A comparative methodology for the 'quality in gender + equality policies' (QUING) project (Working Paper). Retrieved from http://cps.ceu.hu/sites/default/files/publications/cpsworking-paper-critical-frame-analysis-quing-2012.pdf

Eckes, S. E., \& McCarthy, M. M. (2008). GLBT teachers: The evolving legal protections. American Educational Research Journal, 45(3), 530-554. doi: 10.3102/0002831208314764

Espelage, D. L., Aragon, S. R., Birkett, M., \& Koenig, B. W. (2008). Homophobic teasing, psychological outcomes, and sexual orientation among high school students: What influence do parents and schools have? School Psychology Review, 37(2), 202-216.

Evans, R. B. (1969). Childhood parental relationships of homosexual men. Journal of Consulting and Clinical Psychology, 33(2), 129-135.

Fetner, T., \& Kush, K. (2008). Gay-straight alliances in high schools: Social predictors of early adoption. Youth and Society, 40(1), 114-130.

Fischer, F. (2003). Reframing public policy: Discursive politics and deliberative practices. New York, NY: Oxford University Press.

Goodenow, C., Szalacha, L., \& Westheimer, K. I. M. (2006). School support groups, other school factors, and the safety of sexual minority adolescents. Psychology in the Schools, 43(5), 573-589. doi: 10.1002/pits

Graves, K. L. (2009). And they were wonderful teachers: Florida's purge of gay and lesbian teachers. Urbana, IL: University of Illinois Press.

Greenberg, J. S. (1974, October). A study of personality change associated with the conducting of a high school unit on homosexuality. Paper presented at the $48^{\text {th }}$ annual convention of the American School Health Association: New York. doi: http://files.eric.ed.gov/fulltext/ED103761.pdf

Gruber, J. E., \& Fineran, S. (2008). Comparing the impact of bullying and sexual harassment victimization on the mental and physical health of adolescents. Sex Roles, 59(1-2), 1-13. doi: 10.1007/s11199-008-9431-5

Gundlach, R. H. (1969). Childhood parental relationships and the establishment of gender roles of homosexuals. Journal of Consulting and Clinical Psychology, 33(2), 136-139.

Hackford-Peer, K. (2010). In the name of safety: Discursive positioning of queer youth. Studies of Philosophy and Education, 29(6), 541-556.

Hershberger, S. L., \& D'Augelli, A. R. (1995). The impact of victimization on the 
mental health and suicidality of lesbian, gay, and bisexual youths. Developmental Psychology, 31, 65-74.

Hetrick E. S., \& Martin, A. D. (1987). Developmental issues and their resolution for gay and lesbian adolescents. New York, NY: Haworth Press.

Himmelstein, K. E. W., \& Brückner, H. (2010). Criminal-justice and school sanctions against nonheterosexual youth: A national longitudinal study. Pediatrics, 127(1), 49-57. doi: 10.1542/peds.2009-2306

Hooker, E. (1969). Parental relations and male homosexuality in patient and nonpatient samples. Journal of Consulting and Clinical Psychology, 33(2), 140-142.

Hunter, J., \& Schaecher, R. (1990). Gay and lesbian youths. In M. RotheramBorus, J. Bradley, \& N. Oblensky (Eds.), Planning to live: Suicidal youths in community settings (pp. 297-317). Tulsa, OK: University of Oklahoma Press.

Ivey, R. D. (1972). Consultation with a male homosexual. Personnel and Guidance Journal, 50(9), 749-754.

Kahn, M., \& Gorski, P. (2016). The gendered and heterosexist evolution of the teacher exemplar in the United States: Equity implications for LGBTQ and gender nonconforming teachers. International Journal of Multicultural Education, 18(2), 15-38.

Killinger, R. (1971). The counselor and gay liberation. Personnel and Guidance Journal, 49(9), 715-719.

Kosciw, J. G., Greytak, E. A., Diaz, E. M., \& Bartkiewicz, M. J. (2009). GLSEN 2009 national school climate survey. Retrieved from https://www.glsen.org/ sites/default/files/2009\%20National\%20School\%20Climate\%20Survey\%20F ull\%20Report.pdf

Kuypers, J. A. (2009). Rhetorical criticism: Perspectives in action. Landham, MD: Lexington Books.

La Morte, M. W. (1975). Recognition of homosexual organization. NOLPE School Law Journal, 5(1), 48-52.

Lee, C. (2002). The impact of belonging to a high school gay/straight alliance. The High School Journal, 85(3), 13-26.

Liebert, R. (1971). The gay student: A psychopolitical view. Change, 3(6), 38-44.

Maher, M. J., Landini, K., Emano, D. M., Knight, A. M., Lantz, G. D., Parrie, M., ... Sever, L. M. (2009). Hirschfeld to Hooker to Herek to high schools: A study of the history and development of GLBT empirical research, institutional policies, and the relationship between the two. Journal of Homosexuality, 56(7), 921-58. doi:10.1080/00918360903187861

Martin, A. D., \& Hetrick, E. S. (1988). The stigmatization of the gay and lesbian adolescent. Journal of Homosexuality, 15(1/2), 163-183. 
Mathews, W. M. (1973). Homosexuality: An educational confrontation. Paper presented at American Educational Research Association Meeting. New Orleans, Louisiana.

McCabe, P. C., \& Rubinson, F. (2008). Committing to social justice: The behavioral intention of school psychology and education trainees to advocate for lesbian, gay, bisexual, and transgendered youth. School Psychology Review, 37(4), 469-486.

Meyer, I. H., \& Wilson, P. A. (2009). Sampling lesbian, gay, and bisexual populations. Journal of Counseling Psychology, 56(1), 23-31. doi:10.1037/a0014587

Morin, S. F. (1974). Educational programs as a means of changing attitudes towards gay people. Homosexual Counseling Journal, 1(4), 160-165.

Morrison, L. L., \& L'Heureux, J. (2001). Suicide and gay/lesbian/bisexual and transgender students: Implications for clinicians. Journal of Adolescence, 24, 39-49.

Murdock, T. B., \& Bolch, M. B. (2005). Risk and protective factors for poor school adjustment in lesbian, gay, and bisexual (LGB) high school youth: Variable and person-centered analyses. Psychology in the Schools, 42(2), 159-172. doi:10.1002/pits.20054

Ostrander, K. H. (1975). The teacher's duty to privacy: Court rulings in sexual deviancy cases. Phi Delta Kappan, 57(1), 20-22.

Pascoe, C. J. (2007). Dude, you're a fag: Masculinity and sexuality in high school. Berkeley, CA: University of California Press.

Payne, E., \& Smith, M. (2010). Reduction of stigma in schools: An evaluation of the first three years. Issues in Teacher Education, 19(2), 11-36.

Poteat, V. P., Espelage, D. L., \& Koenig, B. W. (2009). Willingness to remain friends and attend school with lesbian and gay peers: Relational expressions of prejudice among heterosexual youth. Journal of Youth and Adolescence, 38, 952-962.

Price, J. H., \& Telljohann, S. K. (1991). School counselors' perceptions of adolescent homosexuals. Journal of School Health, 61(10), 433-438.

Rehm, L. P., \& Rozensky, R. H. (1974). Multiple behavior techniques with a homosexual client: A case study. Journal of Behavior Therapy and Experimental Psychiatry, 5, 53-57.

Remafedi, G., French, S., Story, M., Resnick, M. D., \& Blum, R. (1998). The relationship between suicide risk and sexual orientation: Results of a population-based study. American Journal of Public Health, 88, 57-60.

Remafedi, G. (1987). Adolescent homosexuality: Psychosocial and medical implications. Pediatrics, 79, 331-337.

Rivera, J. R., \& Galvan, R. J. (1975). Homosexuals and Title VII. Texas Southern 
University Law Review, 3(2), 126-140.

Robinson, K. E. (1994). Addressing the needs of gay and lesbian students: The school counselor's role. School Counselor, 41(5), 326-332.

Rotheram-Borus, M.J., Rosario, M., Meyer-Bahlburg, H., Koopman, C., Dopkins, S., \& Davies, M. (1994). Sexual and substance use acts among gay and bisexual male adolescents in New York City. The Journal of Sex Research, 31(1), 47-57.

Russell, S. T., Seif, H., \& Truong, N. L. (2001). School outcomes of sexual minority youth in the United States: Evidence from a national study. Journal of Adolescence, 24(1), 111-27. doi:10.1006/jado.2000.0365

Russell, S. T., Muraco, A., Subramaniam, A., \& Laub, C. (2009). Youth empowerment and high school gay-straight alliances. Journal of Youth and Adolescence, 38, 891-903.

Russell, S. T. (2005). Beyond risk: Resilience in the lives of sexual minority youth. Journal of Gay and Lesbian Issues in Education, 2(3), 5-18.

Sandfort, T. G. M., Bos, H. M. W., Collier, K. L., \& Metselaar, M. (2010). School environment and the mental health of sexual minority youths: A study among Dutch young adolescents. American Journal of Public Health, 100(9), 1696700. doi:10.2105/AJPH.2009.18309

Savin-Williams, R. C. (1994). Verbal and physical abuse as stressors in the lives of lesbian, gay male, and bisexual youths: Associations with school problems, running away, substance abuse, prostitution, and suicide. Journal of Consulting and Clinical Psychology, 62(2), 261-269.

Savin-Williams, R. C. (2005). The new gay teenager. Cambridge, MA: Harvard University Press.

Savin-Williams, R. C. (2009). How many gays are there? It depends. In D. A. Hope (Ed.), Nebraska Symposium on Motivation (Vol. 54): Contemporary perspectives on lesbian, gay, and bisexual identities (pp. 5-41). New York, NY: Springer.

Sievert, W. (1974). Out of the academic closet. Change, 6(3). 22-23.

Talburt, S. (2004). Constructions of LGBT youth: Opening up subject positions. Theory Into Practice, 43(2), 116-121.

te Riele, K. (2006). Youth 'at risk': Further marginalizing the marginalized? Journal of Education Policy, 21(2), 129-145.

Tooms, A. (2007). The right kind of queer: Fit and the politics of school leadership. Journal of School Leadership, 17, 601-630.

U.S. Department of Health and Human Services. (1989). Report of the secretary's task force on youth suicide: Gay male and lesbian youth suicide. Retrieved from http://files.eric.ed.gov/fulltext/ED334503.pdf

Victim Services/Traveler's Aid. (1991). Streetwork projects study. New York, NY: 
Victim Services.

Walls, N. E., Freedenthal, S. \& Wisneski, H. (2008). Suicidal ideation and attempts among sexual minority youths receiving social services. Social Work, 53(1), 21-29.

Walls, N. E., Kane, S. B., \& Wisneski, H. (2010). Gay-straight alliances and school experiences of sexual minority youth. Youth and Society, 41(3), 307-332.

Wilkinson, L., \& Pearson, J. (2009). School culture and the well-being of samesex-attracted youth. Gender \& Society, 23(4), 542-568. doi:10.1177/ 0891243209339913

Williams, T., Connolly, J., Pepler, D. \& Craig, W. (2005). Peer victimization, social support, and psychosocial adjustment of sexual minority adolescents. Journal of Youth and Adolescence, 34(5), 471-482.

Zach, J., Mannheim, A., \& Alfanso, M. (2010) "I didn't know what to say..." Four archetypal responses to homophobic rhetoric in the classroom. High School Journal, 93(3), 98-110.

\section{Author Contact}

Sarah Schneider Kavanagh: skav@uw.edu

University of Washington, College of Education, Curriculum and Instruction022

Odegaard, Seattle, WA 98195-5502 